\title{
¿Es adecuado el consumo alimentario de los luchadores olímpicos? Resultados de un estudio descriptivo
}

\author{
Is the food consumption of the Olympic fighters adequate? \\ Results of a descriptive study \\ O consumo de alimentos dos lutadores olímpicos é adequado? \\ Resultados de um estudo descritivo
}

\author{
Zulma Delgado', Heidy Gaviria', Alyson Guevara', Brigitt Berdugo ${ }^{1 *}$ \\ Recibido: 9 de julio de 2020. Aceptado para publicación: 25 de octubre de 2020 \\ Publicado en línea: 1 de diciembre de 2020 \\ https://doi.org/10.35454/rncm.v4n1.176
}

\section{Resumen}

Introducción: la lucha olímpica es un deporte de combate que se practica en diferentes "divisiones de peso". Existe una tendencia a obtener alguna ventaja física frente a sus rivales tratando de competir en una categoría inferior al peso natural, lo que puede llevar al deportista a conductas alimentarias inadecuadas, lo cual constituye una amenaza para la salud y su rendimiento deportivo.

Objetivo: identificar las características alimentarias y de consumo de alimentos en los distintos períodos de precompetencia, competencia y poscompetencia de deportistas de lucha olímpica.

Materiales y métodos: estudio cuantitativo de tipo descriptivo y corte transversal. Se realizó el recordatorio de 24 horas, el cuestionario de frecuencia de consumo y una encuesta de comportamiento alimentario.

Resultados: la ingesta de energía estuvo por debajo de lo recomendado para el deporte (35,8 g/ $\mathrm{kg} / \mathrm{día})$, al igual que el consumo de proteína en el día previo a la competencia (1,46 g/kg/día). El consumo de los carbohidratos no superó los $6 \mathrm{~g} / \mathrm{kg} /$ día y las grasas en $1,2 \mathrm{~g} / \mathrm{kg} /$ día. En cuanto a los micronutrientes hubo déficit de minerales como sodio, calcio, potasio y zinc. El consumo diario de frutas enteras es del $6 \%$ y de verduras crudas, del $14 \%$.

\section{Abstract}

Introduction: Olympic wrestling is a combat sport practiced in different weight divisions. Among athletes, there is a tendency to gain physical advantage over their rivals by trying to compete in a weight class below their natural weight. This practice can lead the athlete to engage in inappropriate eating behaviors, posing a threat to their health and athletic performance.

Objective: To identify the dietary and food intake characteristics of Olympic wrestling athletes in the pre-competition, competition, and post-competition periods.

Materials and methods: Quantitative, descriptive, cross-sectional study. A 24-hour reminder, and a questionnaire on food intake frequency questionnaire, and a survey on eating behavior were carried out.

Results: Energy intake was below that recommended for athletes $(35.8 \mathrm{~g} / \mathrm{kg} /$ day), as well as protein intake on the day before the competition ( $1.46 \mathrm{~g} / \mathrm{kg} /$ day). of the intake of carbohydrates and fats did not exceed $6 \mathrm{~g} / \mathrm{kg} /$ day and $1.2 \mathrm{~g} / \mathrm{kg} /$ day, respectively. As for micronutrients, there was a deficit of minerals such as sodium, calcium, potassium, and zinc. The daily intake of whole fruits and raw vegetables was $6 \%$ and $14 \%$, respectively.

\section{Resumo}

Introdução: A luta olímpica é um esporte de combate praticado em diferentes "categorias de peso". Existe uma tendência de obter alguma vantagem física sobre os rivais tentando competir em uma categoria inferior ao peso natural, o que pode levar o atleta a comportamentos alimentares inadequados que constituem uma ameaça à saúde e ao desempenho esportivo.

Objetivo: Identificar as características nutricionais e de consumo alimentar nos diferentes períodos de pré-competição, competição e pós-competição de atletas de luta olímpica.

Materiais e métodos: estudo descritivo quantitativo e transversal. Foram realizados o recordatório de 24 horas, o questionário de frequência de consumo alimentar e uma enquete de comportamento alimentar.

Resultados: o consumo energético ficou abaixo do recomendado para o esporte em 35,8 g/ $/ \mathrm{kg} / \mathrm{dia}$, assim como o consumo de proteína na véspera da competição em 1,46 g/kg/dia. O consumo dos carboidratos não ultrapassou os $6 \mathrm{~g} /$ $\mathrm{kg} / \mathrm{dia}$ e as gorduras em 1,2 g/kg/dia. Em relação aos micronutrientes, houve déficit de minerais como sódio, cálcio, potássio e zinco. $\mathrm{O}$ consumo diário de frutas inteiras é de $6 \%$ e de vegetais crus $14 \%$. 
Conclusiones: los luchadores olímpicos, con el fin de ajustar el peso de categoría, recurren a dietas restrictivas marcadas por un desbalance energético y un déficit de macro y micronutrientes esenciales en los días previos o el mismo día de la competición. Se recomienda realizar un seguimiento a estos deportistas por parte de profesionales de la nutrición para evitar dietas inadecuadas, y así mejorar el rendimiento físico.

Palabras clave: lucha libre, dieta, nutrientes, calorías.
Conclusions: To adjust the weight of the class, Olympic wrestlers resort to restrictive diets marked by an energy imbalance and a deficit of essential macro and micronutrients in the days prior to the competition or on the day of the competition. Monitoring of these athletes by nutrition professionals is recommended to avoid inappropriate diets and thus improve physical performance.

Keywords: Olympic Wrestling; Diet; Nutrients; Calories.
Conclusões: Com a finalidade de ajustar o peso da categoria os lutadores olímpicos recorrem a dietas restritivas nos dias antes ou no dia da competição; as quais estão marcadas por um desequilíbrio energético e um déficit de macro e micronutrientes essenciais. O acompanhamento desses atletas por profissionais da nutrição é recomendado para evitar dietas inadequadas e, assim, melhorar o desempenho físico.

Palavras-chave: luta olímpica, alimentação, nutrientes, calorias.
Facultad de Salud y Rehabilitación, Institución Universitaria Escuela Nacional del Deporte. Cali, Valle del Cauca, Colombia.

\section{INTRODUCCIÓN}

La lucha olímpica es un deporte de combate basado en un sistema de divisiones de peso, con el fin de crear un nivel de competencia más equitativo. Existe una tendencia a obtener alguna ventaja física frente a sus rivales al tratar de competir en una categoría inferior al peso natural, lo cual constituye una amenaza para la salud y el rendimiento deportivo ${ }^{(1)}$; por esta razón, muchos atletas utilizan diferentes estrategias para perder peso, entre las que se destacan las restricciones de alimentos, la disminución energética y de ingesta de líquidos, entre otras técnicas. Estas pueden llevar a una deshidratación severa para los deportistas, lo que repercute en el rendimiento deportivo y el estado nutricional ${ }^{(2)}$.

Los problemas o desórdenes alimenticios y nutricionales son comunes en estos deportes, principalmente en los momentos precompetitivo y competitivo, debido a las altas exigencias para llegar a una meta corporal. Estos atletas desconocen los daños que pueden ocasionar en su organismo y salud, incluso en su rendimiento cuando se someten a técnicas que son empíricas y no son las más adecuadas sin la guía o ayuda de un profesional de la nutrición ${ }^{(2)}$.

La guía de dieta para deportistas luchadores de The Maryland Public Secondary Schools Athletic Association (MPSSAA) refiere que los deportistas que bajan de peso a menudo se niegan a sí mismos los nutrientes que necesitan para desempeñarse bien; por lo tanto, una mala nutrición obstaculizará el rendimiento ${ }^{(3)}$. Para aumentar la fuerza, los deportistas necesitan más calorías y nutrientes que satisfagan las demandas del entrenamiento diario. El ayuno hace que el cuerpo use proteínas musculares para obtener energía, limita el crecimiento muscular y el desarrollo de la fuerza; mientras que una dieta adecuada ayudará a los luchadores a perder peso sin sacrificar el tejido muscular ni deshidratarse. Además, bajar de peso rápidamente resulta en una pérdida tanto de tejido muscular como de agua; bajar de peso gradualmente (2-3 libras/semana) es la mejor manera de perder grasa y mantener los músculos. En consecuencia, el entrenamiento adecuado debe incluir una nutrición adecuada todos los días ${ }^{(3)}$.

Es por esto que es importante analizar la alimentación de los deportistas y confrontar si lo que se ingiere es realmente lo necesario para un desempeño deportivo óptimo. Además, este análisis favorecería la implementación de estrategias nutricionales que eviten trastornos alimentarios o prácticas inadecuadas para la pérdida de peso, que pueden ser contrarios a los objetivos propuestos por el deporte ${ }^{(4,5)}$.

El propósito de este estudio fue describir el consumo alimentario en precompetencia, competencia y poscompetencia de los deportistas de la categoría "mayores" de lucha olímpica en una liga de las Fuerzas Armadas de Colombia.

\section{MATERIALES Y MÉTODOS}

Este es un estudio cuantitativo de tipo descriptivo y corte transversal, que evalúa la alimentación de los luchadores olímpicos durante la etapa precompetitiva, competitiva y poscompetitiva en los Juegos Nacionales de 2019. El análisis se realizó en un total de 28 deportis- 
tas que compiten en la categoría "mayores" por divisiones de peso, con entrenamientos de 6 días a la semana y con un mínimo de 2 horas diarias.

Durante tres días, se evaluó la ingesta alimentaria de los deportistas (antes, durante y posterior a la competencia) a través del recordatorio de 24 horas versión 1-Código EP- FR, $050^{(6)}$ y la frecuencia de consumo (FC) adaptada de la ENSIN $2010^{(7)}$. Con el fin de determinar los factores condicionantes de la dieta también se aplicó una encuesta de comportamiento alimentario con 18 preguntas sobre la selección, preparación, horario de toma de alimentos, preferencias de ingestión de alimentos, creencias y barreras al cambio ${ }^{(8)}$. Se estimaron las porciones de alimentos con el atlas fotográfico ${ }^{(9)}$ y la FC de los principales grupos de alimentos (lácteos, huevos, carnes y pescados, leguminosas, frutas, vegetales, cereales, tubérculos, salsas, aceites y otras grasas, azúcares y dulces, comidas rápidas y productos de paquetes).

Se analizó la ingesta de energía y nutrientes con las tablas de composición de alimentos colombianos ${ }^{(10)}$; los resultados se compararon con las recomendaciones de calorías y nutrientes para la lucha olímpica ${ }^{(11-16)}$ y las Recomendaciones de Ingesta de Energía y Nutrientes (RIEN) para la población adulta sana, con un nivel de actividad física vigorosa de 2,05 por tasa metabólica basal $(\mathrm{TMB})^{(17)}$. Cabe señalar que para el deporte es necesario evaluar la ingesta de macronutrientes por $\mathrm{g} / \mathrm{kg} /$ día. La FC se comparó con las recomendaciones de las Guías Alimentarias Basadas en Alimentos para la población colombiana $^{(18)}$ y para la calidad global de la dieta se utilizó el índice de adecuación nutricional (IAN) ${ }^{(17)}$.

Se tomó el peso corporal una semana antes de la competencia para evitar un sesgo por deshidratación o pérdidas rápidas de peso. Para ello, se utilizó una báscula $\mathrm{OMRON}^{\circledR} \mathrm{H} 289$, que cuenta con una precisión de 100 g. Como requisitos se tuvieron en cuenta usar el mínimo de ropa el día previo a la evaluación, no realizar ejercicio físico 6 horas antes y no consumir alimentos ni bebidas 3 horas antes de esta.

\section{Procesamiento de la información}

Sé utilizó el programa STATA IC y Microsoft Excel para MaciOS 13.3; además, se utilizaron códigos de secuencia numérica previamente asignados. Se estimaron la frecuencia relativa y absoluta, las medidas de tendencia central (media, mediana y moda) y medidas de dispersión (rango, varianza, desviación estándar, mínimos y máximos). Se realizó la prueba de normalidad con la prueba de Kolmogórov-Smirnov. Con un nivel de sig- nificancia de 0,05 , se encontró que los datos analizados tienen una distribución normal con valor de $p<0,05$, teniendo como base un valor Alpha de 0,05 , un nivel confianza del $95 \%$ y un margen de error del 0,03.

\section{ASPECTOS ÉTICOS}

El estudio fue aprobado por el Comité de ética de investigación en humanos de la Institución Universitaria Escuela Nacional del Deporte. Es un estudio de riesgo mínimo con una participación voluntaria, garantías de confidencialidad y con la firma del consentimiento informado por parte de los participantes ${ }^{(19)}$.

\section{RESULTADOS}

\section{Características sociodemográficas}

Los deportistas evaluados fueron hombres con una edad media de $28 \pm 7$ años, con edades que oscilan entre los 18 a 43 años. El peso corporal promedio de los luchadores fue de $73,2 \mathrm{~kg} \pm 15 \mathrm{~kg}$; el deportista con menor peso fue de $55 \mathrm{~kg}$ y el de mayor peso de $130 \mathrm{~kg}$ (Tabla 1).

\section{Consumo alimentario}

El promedio de la ingesta calórica fue $2040 \pm 1812 \mathrm{kcal}$ antes de la competencia y hubo un aumento posterior a la misma de hasta $3280 \pm 1385 \mathrm{kcal}$ (Figura 1).

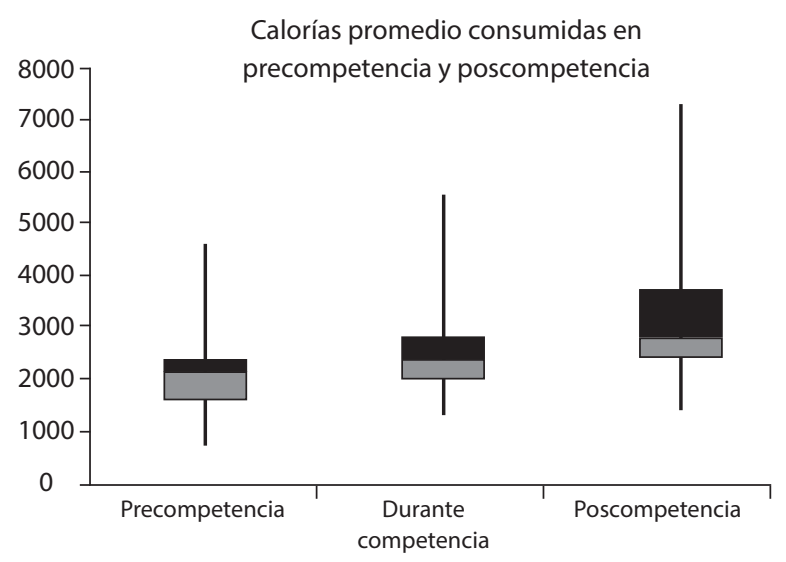

Figura 1. Consumo calórico precompetencia y poscompetencia de los deportistas de lucha olímpica.

En la Tabla 2 se observa el consumo promedio de los tres días analizado con aportes de carbohidratos de 4,6 $\mathrm{g} / \mathrm{kg}$ día, proteína de $1,65 \mathrm{~g} / \mathrm{kg} /$ día y grasas de $1,2 \mathrm{~g} /$ $\mathrm{kg} /$ día, representados por un $19 \%$ de proteína, $31 \%$ 
Tabla 1. Consumo promedio de calorías y de macronutrientes por categoría de peso

\begin{tabular}{|c|c|c|c|c|c|c|c|c|c|c|c|c|c|c|c|}
\hline \multirow{2}{*}{ Peso } & \multirow{3}{*}{$n^{\circ}$} & \multicolumn{2}{|c|}{$\begin{array}{l}\text { Requerimiento } \\
\text { calórico según } \\
\text { peso corporal }\end{array}$} & \multicolumn{4}{|c|}{ Día precompetencia } & \multicolumn{4}{|c|}{ Día de la competencia } & \multicolumn{4}{|c|}{ Día poscompetencia } \\
\hline & & $\begin{array}{l}50 \text { kcal/ } \\
\text { kg peso } \\
\text { corporal/ } \\
\text { día }\end{array}$ & RIEN & Calorías & Proteína & Grasa & $\mathrm{CHO}$ & Calorías & Proteína & Grasa & $\mathrm{CHO}$ & Calorías & Proteína & Grasa & $\mathrm{CHO}$ \\
\hline kg & & Kcal & kcal & Kcal/día & g/kg/día & $\underset{\text { día }}{\mathbf{g} / \mathbf{k g} /}$ & $\begin{array}{c}\text { g/kg/ } \\
\text { día }\end{array}$ & Kcal/día & g/kg/día & $\begin{array}{c}\text { g/kg/ } \\
\text { día }\end{array}$ & $\begin{array}{c}\text { g/kg/ } \\
\text { día }\end{array}$ & Kcal/día & g/kg/día & $\begin{array}{c}\mathbf{g} / \mathbf{k g} / \\
\text { día }\end{array}$ & $\begin{array}{c}\mathbf{g} / \mathbf{k g} / \\
\text { día }\end{array}$ \\
\hline $55-57$ & 2 & 2800 & 3100 & 2287 & 2,2 & 1,3 & 5,0 & 2660 & 2,4 & 1,6 & 5,8 & 5451 & 2,9 & 2,9 & 14 \\
\hline $58-61$ & 4 & 3050 & 3250 & 2361 & 1,8 & 1,3 & 5,0 & 2189 & 1,8 & 1,0 & 4,9 & 2460 & 1,9 & 1,2 & 5,5 \\
\hline $62-65$ & 4 & 3200 & 3450 & 1313 & 2,0 & 2,1 & 5,3 & 2620 & 1,7 & 1,2 & 5,9 & 1962 & 1,4 & 0,8 & 4,8 \\
\hline $66-70$ & 7 & 3400 & 3600 & 2487 & 1,4 & 1,3 & 5,0 & 2731 & 1,9 & 1,3 & 5,0 & 2249 & 1,8 & 1,0 & 3,9 \\
\hline $71-74$ & 3 & 3650 & 3750 & 2295 & 2,0 & 1,2 & 6,4 & 2948 & 1,4 & 1,7 & 4,8 & 2431 & 0,9 & 1,1 & 4,8 \\
\hline 75-79 & 4 & 3850 & 3900 & 3463 & 1,9 & 1,2 & 4,1 & 2856 & 2,3 & 1,3 & 3,8 & 2868 & 1,4 & 1,5 & 4,4 \\
\hline $80-86$ & 2 & 4150 & 4050 & 2982 & 1,2 & 0,9 & 2,2 & 2139 & 1,3 & 0,8 & 3,3 & 2540 & 1,4 & 1,0 & 3,8 \\
\hline $87-97$ & 1 & 4850 & $\mathrm{~N} / \mathrm{A}$ & 1725 & 0,8 & 0,8 & 1,9 & 3113 & 1,2 & 0,9 & 4,9 & 2134 & 0,8 & 0,4 & 3,8 \\
\hline+97 & 1 & 6250 & $\mathrm{~N} / \mathrm{A}$ & 2935 & 1,1 & 0,8 & 2,6 & 4000 & 1,8 & 1,5 & 2,2 & 4411 & 1,3 & 1,0 & 4,8 \\
\hline
\end{tabular}

CHO: carbohidratos; g: gramos; kcal: kilocalorías; kg: kilogramo.

de grasa y $51 \%$ de carbohidratos. La Tabla 3 presenta la media y la desviación estándar del consumo de macro y micronutrientes.

\section{Número de comidas}

La mayoría de los deportistas consumen entre tres y cuatro tiempos de comidas, independiente del período en el que se encuentren (Figura 2), y se resalta que ninguno omite el desayuno. El $50 \%$ consume el refrigerio de la media mañana, el $25 \%$ la media tarde y ninguno consume una merienda posentrenamiento.

\section{Frecuencia de consumo}

Las principales fuentes de proteínas son de origen animal. La FC diario de alimentos como carnes es del $57 \%$, huevos del $46 \%$, lácteos y quesos del $43 \%$, leguminosas del $18 \%$ y, en menor proporción, embutidos y vísceras con un $7 \%$. Las leguminosas y el pescado representan el $75 \%$ de la fuente proteica, con un consumo entre 1 a 3 veces por semana.

Las frutas enteras y las verduras crudas no son alimentos de preferencia entre los deportistas, indepen- diente del período o etapa en la que estos se encuentren. Se observó que solo el $6 \%$ y $14 \%$ de los deportistas, respectivamente, tienen un consumo diario; el $29 \%$ nunca consumen verduras crudas y $18 \%$ nunca comen frutas. Sin embargo, el jugo de fruta tiene una mayor aceptación, con un $46 \%$ de consumo diario.

El $82 \%$ consume cereales como el arroz blanco y pastas todos los días, el $64 \%$ consumen pan y arepa, el $23 \%$ consumen tubérculos y el $11 \%$ consume aceite en las preparaciones, bebidas gaseosas o alimentos de paquete, con una tendencia a su aumento en la frecuencia semanal. El $36 \%$ consumen bebidas como el café o té y el $46 \%$ usa azúcares añadidos en su consumo diario.

El $21 \%$ de los deportistas consume suplementos vitamínicos, entre 1 a 3 tabletas al día.

Los alimentos principalmente elegidos para el desayuno son los lácteos, huevo, café y cereales como la arepa o pan. En el almuerzo y la cena prevalece el arroz y las proteínas de origen animal.

\section{Comportamiento alimentario}

Se encontró que el $62 \%$ elige sus alimentos por el sabor y un $25 \%$ por su contenido nutricional sin tener en 
Tabla 2. Consumo promedio calórico y de macronutrientes consumidos durante las tres etapas evaluadas frente a lo recomendado en $\mathbf{g} / \mathbf{k g} /$ día

\begin{tabular}{|l|c|c|c|c|c|}
\hline \multicolumn{1}{|c|}{ Nutriente } & Recomendado & $\begin{array}{c}\text { Consumo } \\
\text { promedio } \\
\text { precompetencia }\end{array}$ & $\begin{array}{c}\text { Consumo } \\
\text { promedio } \\
\text { competencia }\end{array}$ & $\begin{array}{c}\text { Consumo } \\
\text { promedio } \\
\text { poscompetencia }\end{array}$ & $\begin{array}{c}\text { Consumo } \\
\text { promedio de los } \\
\text { tres días }\end{array}$ \\
\hline Calorías & 50 & $27,90^{*}$ & $34,70^{*}$ & $44,80^{*}$ & $35,78^{*}$ \\
\hline Proteínas & $1,6-2,0^{*}(11-13)$ & $1,46^{*}$ & $1,66^{*}$ & $1,84^{*}$ & $1,65^{*}$ \\
\hline Lípidos & $20-25 \%(13,14)$ & $30 \%$ & $32 \%$ & $30 \%$ & $31 \%$ \\
\hline Carbohidratos & $6,0-10^{*(15,16)}$ & $3,50^{*}$ & $4,25^{*}$ & $6,0^{*}$ & $4,58^{*}$ \\
\hline
\end{tabular}

*kcal/kg/día.

Tabla 3. Consumo calórico y de nutrientes de los deportistas durante las tres etapas evaluadas

\begin{tabular}{|c|c|c|c|c|c|c|c|}
\hline \multicolumn{2}{|c|}{ Recomendaciones para el deporte } & \multicolumn{2}{|c|}{ Precompetencia } & \multicolumn{2}{|c|}{ Durante competencia } & \multicolumn{2}{|c|}{ Poscompetencia } \\
\hline Nutriente & $\begin{array}{l}\text { Recomendación } \\
\text { (RIEN) }\end{array}$ & Media \pm DE & $\begin{array}{c}\text { IAN } \\
\%\end{array}$ & Media \pm DE & $\begin{array}{c}\text { IAN } \\
\%\end{array}$ & Media \pm DE & $\begin{array}{c}\text { IAN } \\
\%\end{array}$ \\
\hline Calorías kcal/día & 3650 & $2040 \pm 812$ & 56 & $2537 \pm 921$ & 69 & $3280 \pm 1385$ & 90 \\
\hline Proteína g/día & 146 & $107 \pm 55$ & 73 & $122 \pm 52$ & 83 & $135 \pm 54$ & 92 \\
\hline Lípido g/día & 73 & $68 \pm 33$ & 92 & $91 \pm 53$ & 124 & $110 \pm 62$ & 150 \\
\hline CHO g/día & 876 & $255 \pm 105$ & 29 & $311 \pm 116$ & 36 & $439 \pm 237$ & 50 \\
\hline Calcio mg/día & $1000^{*}$ & $534,4 \pm 291$ & 366 & $724,4 \pm 505,8$ & 496 & $1047 \pm 822$ & 717 \\
\hline Hierro mg/día & $13^{*}$ & $15,1 \pm 10$ & 4 & $17,6 \pm 9,3$ & 4 & $20 \pm 9,8$ & 5 \\
\hline Sodio mg/día & $1500^{*}$ & $1241 \pm 1021$ & 747 & $1497 \pm 1200$ & 902 & $2054 \pm 1400$ & 1238 \\
\hline Potasio mg/día & $4700 *$ & $2357 \pm 1025$ & 3061 & $2535 \pm 1024$ & 3293 & $3244 \pm 1279$ & 4213 \\
\hline Zinc mg/día & $14^{*}$ & $12 \pm 8,4$ & 6 & $14 \pm 8,3$ & 8 & $14 \pm 9$ & 7 \\
\hline Vit B1 mg/día & $1,2^{*}$ & $1,8 \pm 1,6$ & 0 & $2,0 \pm 1,5$ & 1 & $2 \pm 1,4$ & 1 \\
\hline Vit B2 mg/día & $1,3^{*}$ & $2,1 \pm 1,4$ & 1 & $2,4 \pm 1,5$ & 1 & $3 \pm 1,7$ & 1 \\
\hline Niacina mg/día & $16^{*}$ & $27,8 \pm 20$ & 10 & $27 \pm 14,8$ & 10 & $27 \pm 22$ & 14 \\
\hline $\begin{array}{l}\text { Ácido pantoténico } \\
\text { mg/día }\end{array}$ & $5,0^{*}$ & $6,1 \pm 4,0$ & 4 & $7 \pm 3,0$ & 4 & $7,0 \pm 2,4$ & 4 \\
\hline Vit B6 mg/día & $1,3^{*}$ & $1,9 \pm 1,1$ & 1 & $2,0 \pm 1,0$ & 1 & $2,6 \pm 1,7$ & 1 \\
\hline Ácido fólico $\mu \mathrm{g} /$ día & $400^{*}$ & $374 \pm 264$ & 117 & $389 \pm 238$ & 122 & $443 \pm 281$ & 139 \\
\hline Vit B12 $\mu \mathrm{g} /$ día & $2,4^{*}$ & $4,3 \pm 3,1$ & 1 & $7,6 \pm 7,3$ & 2 & $5,9 \pm 3,7$ & 2 \\
\hline
\end{tabular}

Al: ingesta adecuada; DE: desviación estándar; IAN: índice de adecuación nutricional; *RDA: aporte dietético recomendado; Vit: vitamina.

cuenta las etiquetas nutricionales, ya que solo el $32 \%$ las lee y entiende, el $68 \%$ no las lee por pereza, falta de tiempo o no las entiende.
El $64 \%$ de los deportistas evita los alimentos que no le gustan y el $25 \%$ evita algunos alimentos por salud. La preparación más habitual son los fritos y los asados en 


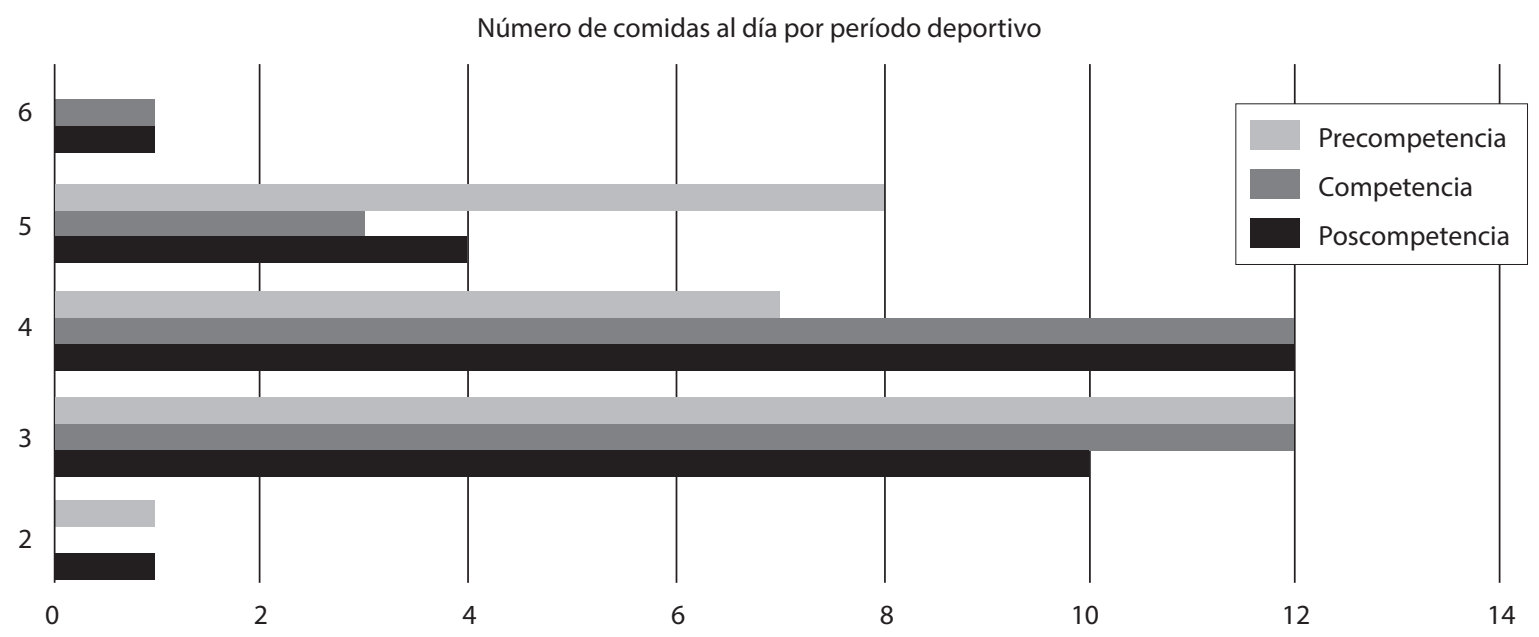

Figura 2. Número de comidas al día de acuerdo con los diferentes períodos deportivos.

el $32 \%$, mientras que el $29 \%$ restante realiza guisados, los cuales son preparados en igual frecuencia por ellos mismos, comprados o preparados por familiares en un $25 \%$. Por su parte, la frecuencia de consumo de alimentos fuera de casa es 1 a 2 veces por semana, con un $36 \%$. El comportamiento alimentario de los deportistas se resume en las Tablas 4 y 5 .

\section{DISCUSIÓN}

Los hábitos alimenticios influencian a gran escala el rendimiento deportivo. Por esta razón, un déficit severo y prolongado en la ingesta de energía y sin la guía de un profesional tendrá repercusiones en la salud y el rendimiento de los deportistas ${ }^{(20,21)}$.

El principal resultado de este estudio muestra que ningún deportista cumplió con la ingesta calórica recomendada para cada período (precompetencia, competencia y poscompetencia), lo cual solo cubre el $56 \%, 69 \%$ y $90 \%$, respectivamente, de las $50 \mathrm{kcal} / \mathrm{kg} /$ día recomendadas. Resultados similares fueron encontrados por Ruales, en donde un grupo de deportistas de taekwondo no cumplieron con la meta calórica y solo el $16 \%$ tuvo una ingesta adecuada, debido a que el grupo que consumió una escasa cantidad de calorías buscaba una reducción en su peso, con el fin de clasificar a una categoría deseada ${ }^{(22)}$; esto también ocurrió en los luchadores olímpicos del presente estudio.

La ingesta energética y de carbohidratos de los deportistas en la etapa de precompetencia presenta un déficit aproximado del $40 \%$ respecto a la de poscompetencia, esto equivale a $1239 \mathrm{kcal}$ que no son ingeridas por los deportistas. Este dato es relevante debido a que hay una relación directa y proporcional entre el aporte de este nutriente y la mejora de los parámetros en el combate ${ }^{(22)}$.

Las estrategias de pérdida de peso de los deportistas luchadores del estudio se basa mayormente en la restricción calórica, similar a los resultados de otros estudios en atletas que presentaron déficits calóricos severos, lo cual los dejó lejos de cumplir con el requerimiento de consumo de carbohidratos en las distintas etapas. Se encontró un consumo del 31,2, 38,6 y 54,5 $\%$, respectivamente, lo cual coincide con lo descrito previamente por nuestro grupo de investigación, con una ingesta promedio de $29 \%, 36 \%$ y $50 \%{ }^{(23)}$.

El consumo de proteína y grasas en los tres períodos fue normal. En el día antes de la competencia se evidenció una disminución en la ingesta de proteína en los deportistas, con un peso por encima de $80 \mathrm{~kg}$, lo cual está por debajo de $1,6 \mathrm{~g} / \mathrm{kg} /$ día, que es lo mínimo para este deporte.

En cuanto a los micronutrientes, las vitaminas cumplen o superan la recomendación; sin embargo, los minerales como el sodio, el calcio, el potasio y el zinc presentan valores insuficientes a los requerimientos en comparación con la recomendación de energía y nutrientes para la población adulta sana, con una ingesta promedio de $2000 \mathrm{kcal} / \mathrm{día}^{\left({ }^{(17)}\right.}$. Este desbalance puede estar asociado con los déficit calóricos y con el bajo consumo de frutas y verduras ${ }^{(18,24)}$.

Según la FC, el huevo parece ser uno de los principales alimentos utilizados para cubrir el requerimiento 
Tabla 4. Resumen de frecuencia de consumo promedio de los deportistas de lucha olímpica

\begin{tabular}{|c|c|c|c|c|}
\hline \multicolumn{5}{|c|}{ Frecuencia de consumo } \\
\hline & Diario & Semanal & Mensual & Nunca \\
\hline Grupo de alimento & $\begin{array}{c}1 \text { a }+3 \text { veces al } \\
\text { día } \\
\%\end{array}$ & $\begin{array}{c}+2 \text { veces a la } \\
\text { semana } \\
\%\end{array}$ & $\begin{array}{c}1 \text { a } 4 \text { veces al } \\
\text { mes } \\
\%\end{array}$ & $\begin{array}{c}\text { No consume } 0<1 \\
\text { vez al mes } \\
\%\end{array}$ \\
\hline Leche (entera, descremada o deslactosada) & 32 & 57 & 4 & 7 \\
\hline Productos lácteos (quesos, yogurt, etc.) & 11 & 75 & 14 & 0 \\
\hline Huevos & 46 & 46 & 0 & 7 \\
\hline Carnes (res, pollo o cerdo) & 57 & 39 & 4 & 0 \\
\hline Pescado (atún y mariscos) & 7 & 75 & 14 & 4 \\
\hline Embutidos (salchichas, chorizos, etc.) & 7 & 54 & 32 & 7 \\
\hline Vísceras (hígado, pajarilla o riñón) & 7 & 14 & 25 & 54 \\
\hline Leguminosas secas (frijol, lentejas, etc.) & 18 & 75 & 4 & 4 \\
\hline Arroz o pastas (blancos) & 82 & 14 & 4 & 0 \\
\hline Arroz o pastas (integrales) & 11 & 14 & 4 & 71 \\
\hline Pan, arepa o galletas (blancos) & 50 & 46 & 0 & 4 \\
\hline Pan, arepa o galletas (integrales) & 14 & 29 & 4 & 54 \\
\hline Tubérculos (papa, yuca o arracacha) y plátanos & 23 & 61 & 4 & 4 \\
\hline Verduras crudas & 14 & 46 & 11 & 29 \\
\hline Verduras cocidas & 7 & 61 & 7 & 25 \\
\hline Frutas en jugo & 46 & 36 & 4 & 14 \\
\hline Frutas enteras & 21 & 54 & 7 & 18 \\
\hline Mantequilla, crema de leche o manteca de cerdo & 11 & 25 & 11 & 54 \\
\hline Café o té & 36 & 43 & 11 & 11 \\
\hline Panela, azúcar y miel & 46 & 39 & 7 & 7 \\
\hline Gaseosas o refrescos & 11 & 64 & 11 & 14 \\
\hline Alimentos de paquete (papas, platanitos o chitos) & 11 & 57 & 11 & 21 \\
\hline Bienestarina & 0 & 14 & 7 & 79 \\
\hline Avena (hojuelas o molida) & 0 & 50 & 14 & 36 \\
\hline Alimentos fritos (empanadas, dedos o buñuelos) & 7 & 54 & 25 & 14 \\
\hline Dulces o golosinas (bombones y gomas) & 7 & 32 & 32 & 29 \\
\hline Suplementos vitamínicos & 21 & 18 & 4 & 57 \\
\hline Comidas rápidas (hamburguesas, perros o pizza) & 4 & 32 & 46 & 18 \\
\hline Utiliza el salero & 7 & 14 & 4 & 75 \\
\hline Alimentos bajos en calorías (light) & 4 & 11 & 4 & 82 \\
\hline
\end{tabular}


Tabla 5. Distribución de frecuencia de los deportistas según comportamientos de consumo

\begin{tabular}{|c|c|c|}
\hline \multicolumn{3}{|c|}{$\begin{array}{l}\text { Comportamiento de consumo } \\
\qquad n=28\end{array}$} \\
\hline Pregunta & Respuesta & $\%$ \\
\hline $\begin{array}{l}\text { ¿Qué factor consideras más importante al elegir } \\
\text { un alimento para su consumo? }\end{array}$ & $\begin{array}{l}\text { Su sabor } \\
\text { Su precio } \\
\text { Que sea agradable a la vista } \\
\text { Su caducidad } \\
\text { Su contenido nutrimental }\end{array}$ & $\begin{array}{c}64 \% \\
4 \% \\
0 \% \\
7 \% \\
25 \%\end{array}$ \\
\hline Me es difícil leer las etiquetas nutrimentales & $\begin{array}{l}\text { Por falta de tiempo } \\
\text { Porque no me interesa } \\
\text { Porque no las entiendo } \\
\text { Por pereza } \\
\text { Sí las leo y las entiendo }\end{array}$ & $\begin{array}{c}11 \% \\
4 \% \\
25 \% \\
29 \% \\
32 \%\end{array}$ \\
\hline $\begin{array}{l}\text { Si evitas algún alimento, ¿por qué motivo lo } \\
\text { haces? }\end{array}$ & $\begin{array}{l}\text { Porque no me gusta } \\
\text { Por cuidarme } \\
\text { Porque me hace sentir mal } \\
\text { No suelo evitar ningún alimento }\end{array}$ & $\begin{array}{c}64 \% \\
25 \% \\
11 \% \\
0 \%\end{array}$ \\
\hline $\begin{array}{l}\text { ¿Cuál es la preparación más habitual de tus } \\
\text { alimentos? }\end{array}$ & $\begin{array}{l}\text { Fritos (incluye empanizados y capeados) } \\
\text { Al vapor o hervidos } \\
\text { Asados o a la plancha } \\
\text { Horneados } \\
\text { Guisados o salteados }\end{array}$ & $\begin{array}{c}32 \% \\
7 \% \\
32 \% \\
0 \% \\
29 \%\end{array}$ \\
\hline $\begin{array}{l}\text { ¿Quién prepara tus alimentos con mayor } \\
\text { frecuencia durante la semana? }\end{array}$ & $\begin{array}{l}\text { Yo } \\
\text { Mi mamá } \\
\text { Los compro ya preparados } \\
\text { Otro }\end{array}$ & $\begin{array}{l}25 \% \\
21 \% \\
25 \% \\
25 \%\end{array}$ \\
\hline $\begin{array}{l}\text { ¿Qué haces normalmente cuando te sientes } \\
\text { satisfecho? }\end{array}$ & $\begin{array}{l}\text { Dejo de comer sin problema } \\
\text { Dejo de comer, pero me cuesta hacerlo } \\
\text { Sigo comiendo sin problema } \\
\text { Sigo comiendo, pero me siento mal de hacerlo }\end{array}$ & $\begin{array}{l}46 \% \\
14 \% \\
29 \% \\
11 \%\end{array}$ \\
\hline ¿Qué haces con la grasa visible de la carne? & $\begin{array}{l}\text { La quito toda } \\
\text { Quito la mayoría } \\
\text { Quito un poco } \\
\text { No quito nada }\end{array}$ & $\begin{array}{l}21 \% \\
43 \% \\
18 \% \\
18 \%\end{array}$ \\
\hline $\begin{array}{l}\text { Habitualmente mastico cada bocado más de } 25 \\
\text { veces }\end{array}$ & $\begin{array}{l}\text { Totalmente en desacuerdo } \\
\text { En desacuerdo } \\
\text { Ni de acuerdo ni en desacuerdo } \\
\text { De acuerdo } \\
\text { Totalmente de acuerdo }\end{array}$ & $\begin{array}{c}18 \% \\
25 \% \\
54 \% \\
4 \% \\
0 \%\end{array}$ \\
\hline $\begin{array}{l}\text { ¿Con quién consumes los alimentos durante la } \\
\text { semana? }\end{array}$ & $\begin{array}{l}\text { Solo } \\
\text { Con amigos } \\
\text { Con la familia }\end{array}$ & $\begin{array}{l}43 \% \\
43 \% \\
14 \%\end{array}$ \\
\hline $\begin{array}{l}\text { ¿Con quién consumes los alimentos durante los } \\
\text { fines de semana? }\end{array}$ & $\begin{array}{l}\text { Solo } \\
\text { Con amigos } \\
\text { Con la familia }\end{array}$ & $\begin{array}{l}11 \% \\
18 \% \\
71 \%\end{array}$ \\
\hline $\begin{array}{l}\text { ¿Qué sueles beber en mayor cantidad durante } \\
\text { el día? }\end{array}$ & $\begin{array}{l}\text { Agua fresca } \\
\text { Agua natural } \\
\text { Refresco, jugos o tés industrializados } \\
\text { Leche } \\
\text { Otro }\end{array}$ & $\begin{array}{c}25 \% \\
29 \% \\
32 \% \\
0 \% \\
14 \%\end{array}$ \\
\hline
\end{tabular}


Tabla 5. Distribución de frecuencia de los deportistas según comportamientos de consumo (continuación)

\begin{tabular}{|c|c|c|}
\hline \multicolumn{3}{|c|}{$\begin{array}{l}\text { Comportamiento de consumo } \\
\qquad n=28\end{array}$} \\
\hline Pregunta & Respuesta & $\%$ \\
\hline $\begin{array}{l}\text { ¿Qué sueles ingerir habitualmente entre } \\
\text { comidas? }\end{array}$ & $\begin{array}{l}\text { Dulces } \\
\text { Fruta o verdura } \\
\text { Galletas o pan dulce (bollería) } \\
\text { Yogurt } \\
\text { Papitas, churritos, frituras, etc. } \\
\text { Cacahuates u otras semillas } \\
\text { Nada }\end{array}$ & $\begin{array}{c}0 \% \\
36 \% \\
32 \% \\
4 \% \\
11 \% \\
0 \% \\
18 \%\end{array}$ \\
\hline $\begin{array}{l}\text { ¿Con qué frecuencia comes alimentos fuera de } \\
\text { casa? }\end{array}$ & $\begin{array}{l}\text { Todos los días } \\
5 \text { a } 6 \text { veces a la semana } \\
3 \text { a } 4 \text { veces a la semana } \\
1 \text { a } 2 \text { veces a la semana } \\
\text { Una vez cada } 15 \text { días } \\
\text { Una vez al mes } \\
\text { Menos de una vez al mes }\end{array}$ & $\begin{array}{c}29 \% \\
7 \% \\
7 \% \\
36 \% \\
18 \% \\
4 \% \\
0 \%\end{array}$ \\
\hline $\begin{array}{l}\text { ¿Con qué frecuencia crees que comes alimentos } \\
\text { en exceso? }\end{array}$ & $\begin{array}{l}\text { Todos los días } \\
5 \text { a } 6 \text { veces a la semana } \\
3 \text { a } 4 \text { veces a la semana } \\
1 \text { a } 2 \text { veces a la semana } \\
\text { Una vez cada } 15 \text { días } \\
\text { Una vez al mes } \\
\text { Menos de una vez al mes }\end{array}$ & $\begin{array}{c}18 \% \\
0 \% \\
18 \% \\
29 \% \\
7 \% \\
21 \% \\
7 \%\end{array}$ \\
\hline $\begin{array}{l}\text { ¿Qué haces o estarías dispuesto a hacer para } \\
\text { cuidar tu cuerpo? }\end{array}$ & $\begin{array}{l}\text { Cuidar mi alimentación } \\
\text { Seguir un régimen dietético temporal } \\
\text { Hacer ejercicio } \\
\text { Cuidar mi alimentación y hacer ejercicio } \\
\text { Tomar suplementos dietéticos o productos herbolarios } \\
\text { Nada }\end{array}$ & $\begin{array}{c}25 \% \\
0 \% \\
29 \% \\
46 \% \\
0 \% \\
0 \%\end{array}$ \\
\hline $\begin{array}{l}\text { ¿Qué consideras que te hace falta para mejorar } \\
\text { tu alimentación? }\end{array}$ & $\begin{array}{l}\text { Más información } \\
\text { Apoyo social } \\
\text { Dinero } \\
\text { Compromiso o motivación personal } \\
\text { Tiempo } \\
\text { Nada, creo que mi alimentación es saludable } \\
\text { No me interesa mejorar mi alimentación }\end{array}$ & $\begin{array}{c}29 \% \\
0 \% \\
36 \% \\
29 \% \\
4 \% \\
4 \% \\
0 \%\end{array}$ \\
\hline ¿Consideras que tu dieta es...? & $\begin{array}{l}\text { Diferente cada día } \\
\text { Diferente solo algunas veces durante la semana } \\
\text { Diferente solo durante los fines de semana } \\
\text { Muy monótona }\end{array}$ & $\begin{array}{l}39 \% \\
25 \% \\
11 \% \\
25 \%\end{array}$ \\
\hline $\begin{array}{l}\text { ¿Crees que eres capaz de utilizar un consejo de } \\
\text { nutrición para mejorar tu estado de salud? }\end{array}$ & $\begin{array}{l}\text { Totalmente en desacuerdo } \\
\text { En desacuerdo } \\
\text { Ni de acuerdo ni en desacuerdo } \\
\text { De acuerdo } \\
\text { Totalmente de acuerdo }\end{array}$ & $\begin{array}{c}14 \% \\
0 \% \\
7 \% \\
54 \% \\
25 \%\end{array}$ \\
\hline
\end{tabular}

de las proteínas, mientras que el pescado es el alimento menos consumido diariamente ${ }^{(25)}$. Otras proteínas vegetales contenidas en las leguminosas tienen un impacto significativo en la dieta de los deportistas, con una ingesta de 3 o más veces/semana, razón por la cual se encontró una estrecha relación con la ingesta pro- 
medio de 2-3 raciones/semana de leguminosas de los deportistas españoles de élite pertenecientes a disciplinas de combate ${ }^{(26)}$.

Los aportes de carbohidratos provienen del arroz blanco (82\%), el pan/arepa/galletas (64\%) y los tubérculos $(57 \%)$. Estos resultados muestran diferencias con lo descrito por la ENSIN 2015 para la población entre 18-64 años, donde se observó la FC del arroz en un $99,2 \%$, pan/arepa/galletas en $88,4 \%$ y los tubérculos en $97,6 \%{ }^{(25)}$.

Respecto a las bebidas gaseosas, el $11 \%$ de los deportistas las consume diariamente y un $64 \%$ semanalmente, lo cual es menor a lo reportado por el Ministerio de Salud en Colombia (22,1 \% de los colombianos consume gaseosas o refrescos dentro de su alimentación diaria y $81,2 \%$ a la semana $)^{(27)}$.

Los deportistas reafirmaron la importancia de la figura del nutricionista dietista para condiciones como leer el etiquetado nutricional, mejorar los hábitos alimenticios y tener un plan alimenticio controlado, para así evitar los ambientes obesogénicos. El estudio de Quiroga demostró que intervenir nutricionalmente a los deportistas les permite aplicar estrategias saludables para obtener el peso deseado, tener un mejor estado de hidratación, equilibrar las pérdidas de energía durante el ejercicio y una recuperación adecuada de los tejidos y de la energía perdida, al igual que potenciar efectos anabólicos $^{(28)}$.

Como limitaciones cabe mencionar el posible sesgo de la información obtenida en el consumo de alimentos el día de la precompetencia, ya que los deportistas pueden omitir información en el recordatorio de 24 horas para ocultar inaniciones o ayunos prolongados. Este estudio no abarca el análisis de la ingesta según el tipo de grasa y carbohidratos (simples y complejos), lo cual sería interesante para futuros estudios.

\section{CONCLUSIONES}

Previamente a la competición, los luchadores olímpicos realizan una dieta restrictiva marcada por una baja ingesta de energía y macronutrientes, principalmente de los carbohidratos, y una ingesta inadecuada de frutas y verduras. El objetivo de esta alimentación restrictiva es obtener preeminencia y clasificar en una división de menor peso. En la etapa de poscompetencia existe un mayor consumo energético, como reacción del organismo para recuperar la falta de energía. La ingesta inadecuada de frutas y verduras puede influir en las deficiencias de algunos micronutrientes esenciales. A pesar de que los deportistas reconocen que la alimentación es importante, sus conductas y percepciones hacia la alimentación en ocasiones no son adecuadas.

\section{RECOMENDACIONES}

- Identificar las estrategias no nutricionales utilizadas para perder peso.

- Incluir en futuros estudios el análisis de las grasas saturadas e insaturadas, así como una evaluación de la disponibilidad energética.

- Aplicar los protocolos de pérdida de peso ya existentes para este tipo de deporte, que incluyan las pautas de alimentación para antes, durante y después de las competencias.

\section{Agradecimientos}

Esta investigación fue desarrollada gracias al apoyo que brindó la Liga de Lucha Olímpica de las Fuerzas Armadas de Santiago de Cali.

\section{Conflicto de intereses}

Declaramos no tener ningún conflicto de interés.

\section{Financiación}

El presente trabajo no tuvo financiación.

\section{Declaración de autoría}

Z. D. y H. G. participaron en la concepción, obtención y análisis de los datos; A.G. participó en la obtención de datos y la interpretación de resultados; B. B. participó en el desarrollo de la investigación, la interpretación de resultados y la redacción del artículo. Todos los autores revisaron el artículo y validaron su versión final.

\section{Referencias bibliográficas}

1. Burke L. Nutrición en el deporte: Un enfoque práctico. Madrid, España: Editorial Médica Panamericana; 2007.

2. Calvo B, García J, Fernández L. Efectos nutricionales de la pérdida de peso a nivel competitivo en deportes de combate [Internet]. UCLM; 2018. [Fecha de consulta: 12 de septiembre de 2019]. Disponible en: http://www.aulamedica.es/gdcr/files/journals/1/articles/7449/submission/ review/7449-9270-1-RV.docx.

3. Landry RV, Oppliger RA, Shetler AC, Landry GL. The Wrestler's Diet: A Guide to Healthy Weight Control [Internet]. Wisconsin Interscholastic Athletic Association. [Fecha de consulta: 3 de mayo 2020] Disponible en: https:// 
www.wiaawi.org/Portals/0/PDF/Sports/Wrestling/wrestlersdiet.pdf.

4. Martínez SJM, Urdampilleta A, Mico L, Soriano JM. Aspectos psicológicos y sociológicos en la alimentación de los deportistas. Cuad. De Psicol. Del Deporte. 2012;12(2):39-48.

5. Hernández GR, Torres LG. Preparación física integrada en deportes de combate. Una revisión. Rev int cienc deporte. 2011;7(Suppl.):31-38.

6. Departamento Administrativo del Deporte, la Recreación, la Actividad Física y el aprovechamiento del Tiempo Libre. Lineamientos de Política Pública en Ciencias del Deportes en Nutrición. Bogotá: COLDEPORTES; 2015.

7. Instituto Colombiano de Bienestar Familiar. Encuesta Nacional de la Situación Nutricional en Colombia 2010 (ENSIN) [Internet]. [Fecha de consulta: marzo 16 de 2019]. Disponible en: https://www.icbf.gov.co/bienestar/nutricion/encuesta-nacional-situacion-nutricional\#ensin2.

8. Márquez-Sandoval YF, Salazar-Ruiz EN, Macedo-Ojeda G, Altamirano-Martínez MB, Bernal-Orozco MF, Salas-Salvado $\mathrm{J}$, et al. Diseño y validación de un cuestionario para evaluar el comportamiento alimentario en estudiantes mexicanos del área de la salud. Nutr Hosp. 2014;30(1):153-64. doi: 10.3305/nh.2014.30.1.7451.

9. Prada G, Herrán Ó, Oróstegui S. Atlas fotográfico de porciones para cuantificar el consumo de alimentos y nutrientes en Santander, Colombia [Internet]. Universidad Industrial de Santander; 2011. [Fecha de consulta: mayo 21 de 2020]. Disponible en: https://ediciones.uis.edu.co/index.php/ publicacionesuis/catalog/book/58.

10. Instituto Colombiano de Bienestar Familiar. Tabla de composición de alimentos colombianos (TCAC) [Internet]. Bogotá, D.C.: Instituto Colombiano de Bienestar Familiar: Universidad Nacional de Colombia; 2015. [Fecha de consulta: 16 de marzo de 2019]. Disponible en: https://www.icbf.gov. co/system/files/tcac_2015_final_para_imprimir.pdf.

11. Hoffman JR, Maresh CM. Nutrition and Hydration Issues for Combat Sport Athletes. Strenght Cond J. 2011;33(6):10-17. doi: 10.1519/SSC.0b013e318237247e.

12. Institute of Medicine. Dietary reference intakes for energy, carbohydrate, fiber, fat, fatty acids, cholesterol, protein, and amino acids. Washington; DC: The National Academies Press; 2005. doi: 10.17226/10490.

13. American College of Sports Medicine, American Dietetic Association, Dietitians of Canada. Joint Position Statement: nutrition and athletic performance. American College of Sports Medicine, American Dietetic Association, and Dietitians of Canada. Med Sci Sports Exerc. 2000;32(12):2130-45. doi: 10.1097/00005768-200012000-00025.

14. Ivy J, Portman R. Programación Nutricional Deportiva. 1. ${ }^{a}$ edición. Barcelona: Paidotribo; 2010.

15. Burke LM, Cox GR. Nutrition in Combat Sports. En: Wallace WA, Wroble RR, Maffulli N, Kordi R. Combat Sports Medicine. Londres: Springer London; 2009. p. 1-20.
16. Jeukendrup A, Gleeson M. Nutrición deportiva. 3. ${ }^{a}$ edición: Tutor; 2019.

17. Ministerio de Salud y Protección Social. Recomendaciones de Ingesta de Energía y Nutrientes (RIEN) para la población colombiana [Internet]; 2016. [Fecha de consulta: 1 de octubre 2020]. Disponible en: https://www.minsalud.gov.co/ sites/rid/Lists/BibliotecaDigital/RIDE/VS/PP/SNA/riendocumento-resumen.pdf.

18. Instituto Colombiano de Bienestar Familiar. Plato saludable de la familia colombiana. Guías Alimentarias Basadas en Alimentos para la población colombiana mayor de 2 años [Internet]. ICBF; 2020. [Fecha de consulta: 21 de mayo de 2020]. Disponible en: https://www.minsalud.gov.co/sites/ $\mathrm{rid} /$ Lists/BibliotecaDigital/RIDE/VS/PP/SNA/guias-alimentarias-basadas-en-alimentos.pdf.

19. Congreso de la República. Ley 1355 de octubre 14 de 2009. Diario oficial No. 47.502 [Internet]. República de Colombia; 14 de octubre de 2009. [Fecha de consulta: marzo 26 de 2019]. Disponible en: https://www.icbf.gov.co/cargues/ avance/docs/ley_1355_2009.htm.

20. Aguinaga RJA. Composición corporal y su relación con la dieta de los deportistas categoría senior de levantamiento de pesas de la concentración deportiva de pichincha, diciembre 2017 a enero 2018 [Internet]. [Tesis de grado]. Universidad de Pontificia Universidad Católica del Ecuador; 2018. [Fecha de consulta: 1 de octubre 2020]. Disponible en: http://repositorio.puce.edu.ec/handle/22000/15028.

21. Santurio MJI, Fernández-Río J. Estudio longitudinal de un kickboxer de élite durante su preparación para los campeonatos de Europa. Retos. 2019;35:20-24. doi: 10.47197/retos. v0i35.62318.

22. Ruales NEE. Relación de la ingesta alimentaria previa a la competencia con el rendimiento deportivo de practicantes de taekwondo de la categoría cadetes seleccionados de la provincia de pichincha [Internet]. [Tesis de grado]. Universidad Católica de Ecuador; 2015. [Fecha de consulta: 1 de octubre 2020]. Disponible en: http://repositorio.puce.edu.ec/handle/22000/10099.

23. Shriver LH, Betts NM, Wollenberg G. Dietary Intakes and Eating Habits of College Athletes: Are Female College Athletes Following the Current Sports Nutrition Standards? J Am Coll Health. 2013;61(1):10-6. doi: 10.1080/07448481.2012.747526.

24. Cortés RPC. Perfil nutricional basado en la composición corporal y hábitos alimentarios de las selecciones deportivas por categorías de peso de la Universidad Nacional de Colombia [Internet]. [Tesis de grado]. Universidad Nacional de Colombia; 2019. [Fecha de consulta: 1 de octubre 2020]. Disponible en: https://repositorio.unal.edu.co/handle/ unal/75667.

25. Herrán OF, Bermudez JN, Zea MP. Cambios alimentarios en Colombia; resultados de dos encuestas nacionales de nutrición, 2010-2015. Rev Univ Ind Santander Salud. 2020;52(1):21-31. doi: 10.18273/revsal.v52n1-2020004. 
26. Úbeda N, Gil-Antuñano PN, Montalvo ZZ, García JB, IglesiasGutiérrez E. Hábitos alimenticios y composición corporal de deportistas españoles de élite pertenecientes a disciplinas de combate. Nutr Hosp. 2010;25(3):414-421. doi: 10.3305/ nh.2010.25.3.4351.

27. Ministerio de Salud y Protección Social. Boletín electrónico para los actores del sistema de salud en Colombia. $\mathrm{N}^{\circ}$ 85 , octubre 24 de 2016. Los impuestos saludables cambiarán comportamientos nocivos para la salud [Internet]. Colombia; 2010. [Fecha de consulta: marzo 14 de 2020].
Disponible en: https://www.minsalud.gov.co/sites/rid/ Lists/BibliotecaDigital/RIDE/DE/COM/Enlace-minsalud85-impuestos-saludables.pdf.

28. Quiroga NJA. Cambios en las prácticas alimenticias de deportistas de judo a partir de la implementación del aprendizaje basado en problemas [Internet]. [Tesis de grado]. Universidad Pedagógica Nacional. Bogotá D. C.; 2019. [Fecha de consulta: 1 de octubre 2020]. Disponible en: http://repository.pedagogica.edu.co/handle/20.500.12209/10833. 